\title{
Comparison of effectiveness of Halo-femoral traction after anterior spinal release in severe idiopathic and congenital scoliosis: a retrospective study
}

\author{
Yong Qiu*, Zhen Liu, Feng Zhu, Bin Wang, Yang Yu, Zezhang Zhu, \\ Bangping Qian and Weiwei Ma
}

Address: Spine Surgery, Drum Tower Hospital, Nanjing University Medical School, Nanjing, China

Email: Yong Qiu* - scoliosis2002@sina.com; Zhen Liu - drliuzhen@163.com; Feng Zhu - cnspine@hotmail.com; Bin Wang - scoliosis2002@sina.com; Yang Yu - scoliosis2002@sina.com; Zezhang Zhu - zhuzezhang@126.com; Bangping Qian - qianbangping@163.com; Weiwei Ma - maweiwei7899@vip.sina.com

* Corresponding author

Published: 30 November 2007

Journal of Orthopaedic Surgery and Research 2007, 2:23 doi:10.1 186/1749-799X-2-23

This article is available from: http://www.josr-online.com/content/2/l/23

(C) 2007 Qiu et al; licensee BioMed Central Ltd.

This is an Open Access article distributed under the terms of the Creative Commons Attribution License (http://creativecommons.org/licenses/by/2.0), which permits unrestricted use, distribution, and reproduction in any medium, provided the original work is properly cited.
Received: 26 December 2006

Accepted: 30 November 2007

\begin{abstract}
Background: Halo-femoral traction could gradually improve the coronal and sagittal deformity and restore the trunk balance through the elongation of the spine. The purpose of this retrospective study was to assess the effectiveness of Halo-femoral traction after anterior spinal release in the management of severe idiopathic and congenital scoliosis.
\end{abstract}

Methods: Sixty patients with severe and rigid curve treated with anterior spinal release, Halo-femoral traction, and second stage posterior spinal fusion were recruited for this retrospective study. Idiopathic Scoliosis (IS) group was 30 patients ( 23 females and 7 males) with mean age of 15.5 years. The average coronal Cobb angle was $91.6^{\circ}$ and the mean global thoracic kyphosis was $50.6^{\circ}$. The curve type of these patients were 2 with Lenke IAN, 4 with Lenke IA+, I with Lenke IBN, I0 with Lenke ICN, 3 with Lenke $\mathrm{IC}+, 3$ with Lenke $3 \mathrm{CN}, 3$ with Lenke $3 \mathrm{C}+$, and 4 with Lenke $5 \mathrm{C}+$. Congenital Scoliosis (CS) group included 30 patients ( 20 females and 10 males) with average age of 15.2 years. The average coronal Cobb angle of the main curve before operation was $95.7^{\circ}$ and the average thoracic kyphosis was $70.2^{\circ}$. All patients had a minimum 12-month follow-up radiograph (range 12-72 months, mean 38 months).

Results: The average traction time was 23 days and the average traction weight was $16 \mathrm{~kg}$. Four patients experienced brachial plexus palsy and complete nerve functional restoration was achieved at two months follow-up. For the IS group, the post-operative mean Cobb angle of major curve averaged $40.1^{\circ}$ with correction rate of $57.5 \%$. For the CS group, the post-operative mean Cobb angle was $56.5^{\circ}$ with average correction rate of $45.2 \%$. The difference in curve magnitude between the IS and CS patients after posterior correction was statistically significant $(\mathrm{t}=4.15, \mathrm{p}<0.00 \mathrm{I})$. The correction rate of kyphosis between IS and CS patients was also statistically significant $(t=-2.59, p<0.016)$.

Conclusion: Halo-femoral traction was a safe, well-tolerated and effective method for the treatment of severe and rigid scoliosis patients. The posterior correction rate obtained after anterior release and traction was significant superior than that recorded from side bending film in current study. 


\section{Background}

With the usage of third-generation spinal instrumentation such as CDH, ISOLA and TSRH, the curve correction obtained from posterior spinal fusion had a significant improvement $[1,2]$. However, the management of severe and rigid scoliosis remained a big challenge to spine surgeon. Preoperative traction could be one option to provide better correction of the rigid spinal deformity and minimize neurological complications associated with forceful intra-operative distraction. Some authors had studied the usage of Halo-femoral traction as one of the preparative treatment prior to posterior reconstructive surgery for severe scoliosis, especially for those with respiratory dysfunction. Halo-femoral traction could gradually improve the coronal and sagittal deformity and restore the trunk balance through the elongation of the spine. Respiratory function improvement was also reported [3-5]. The purpose of this retrospective study was to assess the effectiveness of Halo-femoral traction after anterior spinal release in the management of severe idiopathic and congenital scoliosis.

\section{Methods}

A total of 60 patients with severe and rigid curve and with detailed follow-up data were recruited for this retrospective study. All these patients were treated with anterior spinal release, halo-femoral traction and second stage posterior spinal fusion in authors' hospital from August 1998 to May 2005. The inclusive criteria were as following: congenital scoliosis or idiopathic scoliosis; halo-femoral traction only performed after one stage anterior spinal release and removed before posterior surgery; no history of previous spinal surgery and a minimum postoperative follow-up of 12-month. Standing long-cassette antero-posterior (AP) and lateral radiographs of the whole spine were taken before anterior surgery, 10 days, 12-month after posterior surgery and at final follow-up respectively. Coronal Cobb angles were measured on standing AP film and side bending film. Thoracic kyphosis was measured on the lateral radiograph between the upper endplate of T5 vertebra and the lower endplate of T12 vertebra using the Cobb method [6]. All patients had a minimum 12-month follow-up (range 12-72 months, mean 38 months).

Idiopathic Scoliosis (IS) group included 30 patients (23 females and 7 males). The age at surgery ranged from 10 years to 20 years old with mean age of 15.5 years old. The average coronal Cobb angle was $91.6^{\circ}$ (ranged $70^{\circ}-$ $\left.146^{\circ}\right)$, and the mean global thoracic kyphosis was $50.6^{\circ}$ (ranged $26-100^{\circ}$ ). The curve type of these patients were analyzed [7], and there were 2 with Lenke $1 \mathrm{AN}, 4$ with Lenke $1 \mathrm{~A}+, 1$ with Lenke $1 \mathrm{BN}$, 10 with Lenke $1 \mathrm{CN}, 3$ with Lenke $1 \mathrm{C}+, 3$ with Lenke $3 \mathrm{CN}$, 3 with Lenke $3 \mathrm{C}+$, and 4 with Lenke 5C+. Congenital Scoliosis (CS) group had 30 patients (20 females and 10 males). According to the classification of congenital scoliosis [8], 8 patients were classified as defect of formation, 6 patients as defect of segmentation and 16 patients had combined anomaly. The average age of the patients was 15.2 years (ranged 1020). The average coronal Cobb angle of the main curve was $95.7^{\circ}$ (range $70^{\circ}-150^{\circ}$ ) and the average thoracic kyphosis was $70.2^{\circ}$ (range $28^{\circ}-155^{\circ}$ ) pre-operatively.

All sixty patients received first stage anterior spinal release with the traditional thoracotomy approach and postoperative Halo-femoral traction. None of congenital scoliosis patients were experienced excision of hemivertebra. Traction was usually started the second after anterior surgery with a weight of $2 \mathrm{~kg}$ and gradually increased at a rate of 2 to 3 pounds per day if patients well tolerated. The maximum traction weight could be $33 \%$ to $50 \%$ of the whole body weight depending on patients' tolerance. Traction was applied for a minimum of 12 hours per day, with the traction weight lessened to $50 \%$ in the night. During the traction, the patient's neurological status was frequently checked. If hyper reflex of the extremities, Babinski sign, paresthesia, dysfunction of cranial nerves or any other neurological compromise were noted, the weight would be immediately reduced. The length of the traction period was mainly determined by the radiographic evidence of curve improvement on weekly radiographs, in addition to clinical evaluation of the patients' pulmonary and neurological function. Second stage posterior corrective surgery with $\mathrm{CD}, \mathrm{CDH}$ or TSRH instrumentation were performed after Halo-femoral traction were removed and all the sixty patients with scoliosis surgically were treated by hybrid constructs with hooks and screws.

Statistical analysis was performed for each dependent variable comparing the IS versus CS patients by an independent group's t test. All tests results with $\mathrm{P}<0.05$ were considered statistically significant.

\section{Results}

The average days with halo-femoral traction were similar for IS $(22 \pm 6.3)$ and CS $(25 \pm 9.4)$ patients. The average traction weight was $16 \mathrm{~kg}$, which accounts for $38 \%$ (range $15-50 \%)$ of patients' total body weight. Four patients suffered from brachial plexus palsy (1 CS patient and 3 IS patients), complete nerve function restoration were achieved at two months follow-up after rehabilitation training.

No significant differences were found between the two groups with respect to age or gender distribution. For the IS group, the average pre-operative major curve magnitude was $91.6^{\circ}$ (ranged $70^{\circ}-146^{\circ}$ ) and decreased to $71.7^{\circ}$ (ranged $45^{\circ}-120^{\circ}$ ) on side bending (average cor- 
rection rate: $24.3 \%$ ). The major curve averaged $58.1^{\circ}$ (range $37^{\circ}-90^{\circ}$ ) at the end of the Halo-femoral traction treatment and the average correction rate obtained was $39.3 \%$ (ranged 28.6\%-50.6\%), then improved to $40.1^{\circ}$ (ranged $20^{\circ}-65^{\circ}$ ) after posterior corrective surgery. The mean Cobb's angle at final follow-up was $42.9^{\circ}$ (ranged $\left.24^{\circ}-66^{\circ}\right)$. The mean loss of correction was $2.9 \% \pm 2.3 \%$ (Figure 1 ).

For the 30 cases with CS, initial coronal Cobb angle averaged $95.7^{\circ}$ (range $70^{\circ}-150^{\circ}$ ). The curve magnitude on bending film averaged $73.8^{\circ}$ (range $45^{\circ}-130^{\circ}$ ) with average correction rate of $22.5 \%$ (ranged $6.5 \%-37.8 \%$ ). At the end of the Halo-femoral traction treatment the Cobb's angle averaged $68.4^{\circ}$ (ranged $40^{\circ}-115^{\circ}$ ) and the correction rate averaged $35.3 \%$ (ranged $23.3 \%-50.0 \%$ ). The curve reduced to $56.5^{\circ}$ (ranged $35^{\circ}-110^{\circ}$ ) immediately after posterior surgery and to $58.9^{\circ}$ (ranged $\left.37^{\circ}-112^{\circ}\right)$ at final follow-up. The average loss of correction was $3.2 \% \pm$ $2.1 \%$. The average pre-operative coronal Cobb angle and the average time in Halo-femoral traction were similar for IS and CS patients. The difference in curve magnitude between the IS and CS patients after posterior correction was statistically significant $(\mathrm{t}=4.15, \mathrm{p}<0.001)$ (Figure 2 ).

Improvement on global sagittal alignment was also observed in IS and CS patients. For IS patients, the mean preoperative thoracic kyphosis was $50.6^{\circ}$ (ranged $26^{\circ}-$ $100^{\circ}$ ), which improved to $30.6^{\circ}$ (ranged $22^{\circ}-50^{\circ}$ ) after posterior surgery, and was maintained as $31.6^{\circ}$ (ranged $21^{\circ}-52^{\circ}$ ) at final follow-up. For CS cases, initial mean thoracic kyphosis was $70.2^{\circ}$ (ranged $28^{\circ}-155^{\circ}$ ) and decreased to $39.0^{\circ}$ (ranged $11^{\circ}-82^{\circ}$ ) post-operatively. Before anterior release, the magnitude of thoracic kyphosis of CS patients was larger than that of IS cases $(t=-2.21$, $\mathrm{p}=0.041$, Table 1$)$. After posterior surgery, the difference of the correction rate of kyphosis between IS and CS patients was also statistically significant $(\mathrm{t}=-2.59, \mathrm{p}<$ 0.016, Table 1).

\section{Discussion}

With the development of the spinal corrective techniques and the advancement of the instrumentation, severe and rigid scoliosis which used to be difficult to correct became manageable. At present, the definition of severe scoliosis remains controversial. Greiner et al. [9]determined that AIS patients did not exhibit clinically significant respiratory symptoms until their curves were 60 to $100^{\circ}$, so he defined severe scoliosis as Cobb angle larger than $60^{\circ}$. Lenke et al. [10] have defined it as Cobb angle $\geq 70^{\circ}$, and Tokunaga [11] thought that Cobb angle $>80^{\circ}$ could be treated as severe scoliosis. As for the rigid scoliosis, its definition was also unclear until recently. According to author's clinical experience, the results of one stage posterior surgery for the scoliosis with a coronal Cobb angle less than 70 degrees and a flexible index on Bending films more than $40 \%$ was satisfactory. Therefore, patients with severe and rigid scoliosis were recruited in current study with a coronal Cobb angle larger than $70^{\circ}$ and flexible index on bending films less than $40 \%$.

The aim of the anterior spinal release was to increase spinal flexibility and to improve subsequent correction rate at posterior instrumentation $[12,13]$. Tokunaga et al. [11] reported that staged surgery including anterior release was an effective surgical method for patients with severe scoliosis, where a rigid curve or the risk of neurological complications due to acute forceful correction may exist. Mehlman et al.[14]also reported that the spinal release and halo-femoral traction protocol outlined offer a safe, controlled approach to the reduction of severe spine deformities before fusion. In current study all the patients received anterior spinal release first.

Traction as a method of correction of spinal deformity could be dated back to 3500 BC [15]. Perry and Nickel first introduced the halo device in 1959 [16] during which time a jacket or cast was used for caudal support. Then several other count-traction methods were invented: halogravity, halo-pelvic and halo-femoral traction [17-19]. In terms of halo-femoral traction, Kane et al. [20] reported their series of 30 scoliotic patients in 1967. The average original curve measured $112^{\circ}$ and reduced to $58^{\circ}$ after final correction. Four patients got pin-site irritation and the pins were reinserted. Paresthesia developed in 3 patients, and 1 had abducens nerve palsy; all the symptoms recovered with the reduction of traction forces. Details about the types of curves treated and specific treatment regimens were not provided in this paper. Bonnett et al. [21] reported that preoperative halo-femoral traction resulted in 57\% correction of scoliosis as well as 53\% correction of pelvic obliquity in 37 patients with paralytic scoliosis. Arlet et al. [22] reported on the usage of halofemoral traction to treat a 17-year-old girl with congenital scoliosis of $145^{\circ}$ and cor pulmonale. Correction of the deformity and improvement in pulmonary function were well achieved. Huang et al. [15] reported on the usage of intra-operative halo-femoral traction to treat severe scoliosis and associated pelvic obliquity in a 14-year-old patient with cerebral palsy. The patient underwent one stage anterior and posterior spinal fusion, the posterior procedure was performed with the patient under halofemoral traction. The patient responded well to the surgical intervention and had a stable correction of his pelvic obliquity. Mehlman et al. [14] assessed the effectiveness of spinal release and halo-femoral traction in the management of severe spinal deformity in 2004. Twenty-four patients were treated with halo-femoral traction at the interval between anterior spinal release and posterior surgery. The etiology of the deformity included IS, CS, 

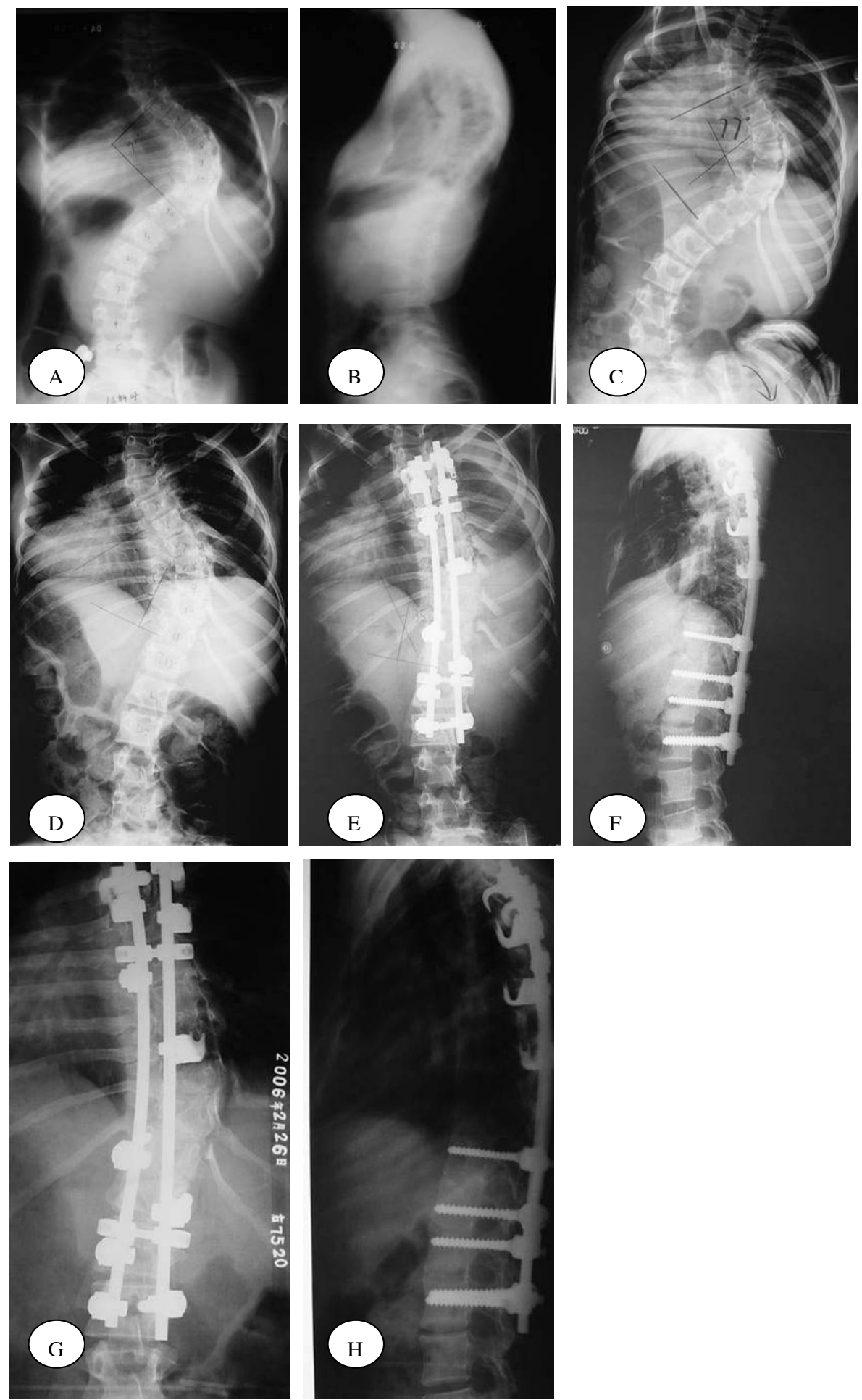

\section{Figure I}

A I4-year-old girl with idiopathic scoliosis and the Lenke classification was IC+. A-B: AP radiographs before treatment showing right thoracic scoliosis measured $92^{\circ}$. C:Bending films showed right thoracic scoliosis corrected to $77^{\circ}$. D:The right thoracic curve correction obtained with Halo-femoral traction treatment was $40.2 \%$. E-F:The major curve measured $35^{\circ}$ after posterior spinal fusion and the correction rate was $62 \%$. G-H: AP and lateral radiographs at 20-month follow-up showed solid spinal fusion with a $37^{\circ}$ right thoracic curve. 

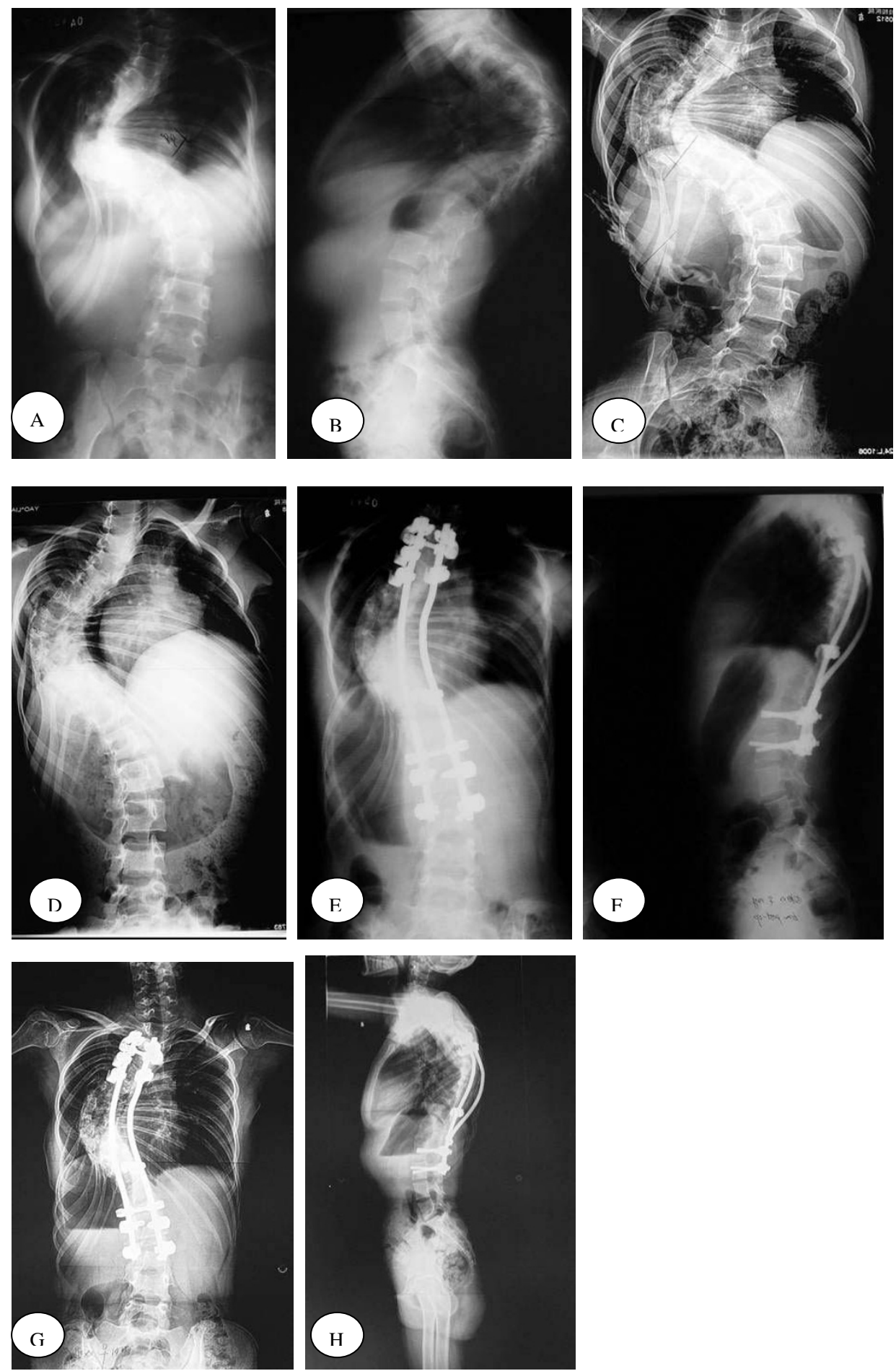

Figure 2

A 13-year-old girl with congenital scoliosis with defect of formation and segmentation. A-B: AP radiographs before treatment showed left thoracic scoliosis measured $98^{\circ}$ and thoracic kyphosis measured $85^{\circ}$. C:Bending films showed right thoracic scoliosis only corrected to $90^{\circ}$. D:The left thoracic curve correction obtained with Halo-femoral traction was 24 . I\%. E-F:The major curve measured $50^{\circ}$ after posterior spinal fusion with correction rate of $49.0 \%$. The correction rate of kyphosis was $47.1 \%$. G$\mathrm{H}$ : AP and lateral radiographs at I8-month follow-up showed solid spinal fusion with a $53^{\circ}$ left thoracic curve and a $45^{\circ}$ thoracic kyphosis. 
Table I: Clinical datas of the IS and CS groups

\begin{tabular}{|c|c|c|c|c|c|c|c|c|c|c|}
\hline Group & $\mathrm{n}$ & $\begin{array}{l}\text { Time in } \\
\text { Halo-femoral } \\
\text { traction(days) }\end{array}$ & $\begin{array}{l}\text { Initial Coronal } \\
\text { Cobb Angle }\left({ }^{\circ}\right)\end{array}$ & 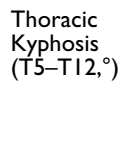 & $\begin{array}{l}\text { Curve } \\
\text { Correction } \\
\text { With Bending } \\
\text { film(\%) }\end{array}$ & $\begin{array}{l}\text { Cobb Correction } \\
\text { After Halo-Femoral } \\
\text { Traction (\%) }\end{array}$ & $\begin{array}{l}\text { Cobb } \\
\text { Correction } \\
\text { After } \\
\text { Posterior } \\
\text { Fusion(\%) }\end{array}$ & $\begin{array}{l}\text { Thoracic } \\
\text { Kyphosis } \\
\text { correction } \\
\text { After Posterior } \\
\text { Fusion } \\
\text { (T5-TI2, \%) }\end{array}$ & $\begin{array}{l}\text { Loss of } \\
\text { Correction } \\
\text { (Coronal\%) }\end{array}$ & $\begin{array}{l}\text { Loss of } \\
\text { Correction } \\
\text { (Sagittal\%) }\end{array}$ \\
\hline IS & 30 & $22 \pm 6.3$ & $91.6 \pm 20.1$ & $50.6 \pm 18.4$ & $24.3 \pm 8.2$ & $39.3 \pm 6.24$ & $57.5 \pm 8.37$ & $33.7 \pm 12.8$ & $2.9 \pm 2.3$ & $2.3 \pm 2.1$ \\
\hline CS & 30 & $25 \pm 9.4$ & $95.7 \pm 24.5$ & $70.2 \pm 34.3$ & $22.5 \pm 11.7$ & $35.3 \pm 7.27$ & $45.2 \pm 8.97$ & $43.5 \pm 14.2$ & $3.2 \pm 2.1$ & $2.5 \pm 1.9$ \\
\hline $\mathrm{t}$ & - & -0.25 & -0.27 & -2.21 & 1.34 & 1.36 & 4.15 & -2.59 & -0.73 & -1.38 \\
\hline$P$ & - & 0.64 & 0.81 & $0.04 I^{*}$ & 0.19 & 0.18 & $<0.001 *$ & $0.016 *$ & 0.28 & 0.18 \\
\hline
\end{tabular}

$*: p<0.05$

Scheuermann's kyphosis, Neuromuscular scoliosis, and Osteogenesis imperfecta. The correction obtained after Halo-feromal traction averaged 59\% (ranged 14-100\%).

In current series, compared with CS with similar curve magnitude, the patients with severe and rigid idiopathic scoliosis were slightly more flexible on side bending film (IS $24.3 \%$ correction vs. CS $22.5 \%$ ). Curve correction obtained after traction has a significant improvement when compared with the correction obtained from side bending film in our study. This statistically significant difference confirms the efficacy of the technique of Halofemaral traction. We also found that the average correction obtained from posterior fusion was $57.5 \%$ in IS group, significantly higher than that in CS group (45.2\%, $\mathrm{p}<0.001$ ). Current results demonstrated less overall curve correction rate when compared with the reports of Kane et al. [20], Bonnett et al. [21] and Mehlman et al. [14]. This may be due in part to lower traction forces used in our study (only $36 \%$ of the average body weight) than Mehlman study ( $54 \%$ of the average body weight). Furthermore, the curves in Kane and Bonnett's study were less rigid than current study.

Leatherman [23] first described a two-stage procedure for the treatment of congenital scoliosis. In his study, the mean curve correction obtained after the second stage was $45.6 \%$ and the correction of kyphosis was $44.4 \%$. Author's results demonstrate that after posterior surgery the curve correction obtained averaged $45.2 \%$ and the thoracic kyphosis magnitude decreased to $39.0^{\circ}$ (ranged $\left.11^{\circ}-82^{\circ}\right)$ with average correction rate of $43.5 \%$. Although the curve correction rate in two studies were similar, the initial curve angel of CS patients in current study were far more serious than that in Leatherman's study. Therefore we could conclude that Halo-femaral traction had a enormous effectiveness for the correction of patients with severe and rigid congenital scoliosis.

Severe coronal curve usually associated with significant deformity on sagittal plane. In current study, twenty-three patients with IS and twenty-five CS patients had pre-oper- ative thoracic kyphosis (T5-T12 > 40 ${ }^{\circ}$ ). Compared with the IS patients, the mean pre-operative thoracic kyphosis for CS was significant higher $\left(70.2^{\circ} v\right.$ s. $\left.50.6^{\circ}\right)$. Combined with Halo-femoral traction, modern spinal instrumentation system provided good correction on sagittal plane for severe scoliosis. Thoracic kyphosis of patients in our study corrected well after posterior surgery, especially for CS patients.

Complications related to the halo itself included pin loosening, superficial, and deep pin tract infections. Brain abscess has also been previously described with halo pins [24]. Halo-femoral traction compiled certain neurological complications [25]. Rinella [26] reported a total of 42 consecutive patients with severe operative scoliosis, kyphoscoliosis, or kyphosis treated with halo-gravity traction. Triceps palsy $(2.38 \%)$, and brachial plexus palsy $(2.38 \%)$ occurred during halo traction. Traction-related complications were also encountered in our study. In the present study, 4 cases suffered from brachial plexus palsy (1 CS patients, 3 IS patients). All patients restored their complete neural function at two months follow-up. The most likely cause of the injury was thought to be due to the hyper-abduction of the arm and over-stretched of the brachial plexus. Brachial plexus palsy associated with Halo-femoral traction in severe and rigid scoliosis was a temporary, revertible damage to nerve function. If the symptoms were promptly detected and rehabilitation training and appropriate medication were prescribed timely, complete nerve functional restoration could be achieved.

Spinal cord injury and paralysis were the most serious complications of spinal corrective surgeries. Cotrel [27] reported that the incidence was $0.8 \%$. Patients with severe and rigid scoliosis were thought to be at greater risk of these complications. Some authors advocated rapid correction via one stage anterior release and posterior surgery for patients with severe scoliosis without an intervening period of traction [28]. Long term follow-up and big sample size were mandatory to support these one-stage or "rapid correction" conception. Our results showed that 
Halo-femoral traction was a safe, well-tolerated and efficacious method in the treatment of this formidable disease. Combined with anterior spinal release and posterior fusion, it could notably reduce the incidence of severe complication such as spinal cord injury, at the time of good correction of severe spinal deformity. In addition, curve correction obtained after traction was significantly superior than that achieved on side bending film in current study, therefore the pre-operative side bending radiography may not able to accurately predict the correction rate of posterior instrumentation for severe scoliosis.

\section{Conclusion}

Halo-femoral traction was a safe and effective method for the treatment of severe idiopathic and congenital scoliosis patients, especially for IS patients. The posterior correction rate obtained after anterior release and traction was significant superior than that recorded from side bending film in current study.

\section{Competing interests}

The author(s) declare that they have no competing interests.

\section{Acknowledgements}

The research was approved by Ethic Committee of Nanjing University.

\section{References}

I. Benli IT, Aka S, Kis M, Citak M, Aydin E, Duman E: Frontal and sagittal balance analysis of late onset idiopathic scoliosis treated with third generation instrumentation. Kobe J Med Sci 200I, 47:23I-253.

2. Suk SI, Kim WJ: Indications of proximalthoracec curve fusion in thoracic adolescent idiopathic scoliosis: recognition and treatment of double thoracic curve pattern in adolescent idiopathic scoliosis treated with segmental instrumentation. Spine 2000, 25:2342-2350.

3. Sink EL, Karol LA, Sanders J, Birch JG, Johnston CE, Herring JA: Efficacy of perioperative Halo-gravity traction in the treatment of severe scoliosis in children. J Pedia Orthop 200I, 21:519-524.

4. Qian BP, Qiu Y, Wang B: Brachial plexus palsy associated with halo traction before posterior correction in severe scoliosis. Stud Health Technol Inform 2006, I 23:538-542.

5. Liljenqvist U, Lepsien U, Hackenberg L, Niemeyer T, Halm H: Comparative analysis of pedicle screw and hook instrumentation in posterior correction and fusion of idiopathic thoracic scoliosis. Eur Spine / 2002, I I :336-343.

6. Cobb J: Outline for the study of scoliosis. AAOS Instr Course Lect 1948, 5:26I-275.

7. Lenke LG, Betz RR, Harms J, Bridwell KH, Clements DH, Lowe TG, Blanke K: Adolescent idiopathic scoliosis: a new classification to determine extent of spinal arthrodesis. J Bone Joint Surg Am 200I, 83-A(8): I|69-1|8|.

8. McMaster MJ, Ohtsuka K: Thenatural history of congenital scoliosis. A study of two hundred and fifty one patients. J Bone Joint Surg Am 1982, 64: I | 28-1 | 47

9. Greiner KA: Adolescent idiopathic scoliosis: radiologic decision-making. Am Fam Physician 2002, 65:1817-1822.

10. O'Brien MF, Lenke LG, Bridwell KH, Blanke K, Baldus C: Preoperative spinal canal investigation in adolescent idiopathic scoliosis curves $\geq 70^{\circ}$. Spine 1994, 19:1606-1610.

11. Tokunaga M, Minami S, Kitahara H, Isobe K, Nakata $\mathrm{Y}$, Moriya H: Vertebral decancellation for severe scoliosis. Spine 2000, 25:469-474.

12. Newton PO, Wenger DR, Mubarak SJ, Meyer RS: Anterior release and fusion in pediatric spinal deformity. A comparison of early outcome and cost of thoracoscopic and open thoracothmy approaches. Spine 1997, I 2:1398- I 409.

13. Newton PO, Shea KG, Granlund KF: Defining the pediatric spinal thoracoscopy learning curve : sixty-five consecutive cases. Spine 2000, 25: 1028-1035.

14. Mehlman CT, Al-Sayyad MJ, Crawford AH: Effectiveness of Spinal Release and Halo-Femoral Traction in the Management of Severe Spinal Deformity. J Pediatr Orthop 2004, 24:667-673.

15. Huang MJ, Lenke LG: Scoliosis and severe pelvic obliquity in a patient with cerebral palsy: surgical treatment utilizing halofemoral traction. Spine 200I, 26:2168-2170.

16. Nickel V, Perry J, Garrett A: The halo - a spinal skeletal traction fixation device. J Bone Joint Surg Am 1968, 50: 1400-I409.

17. Dewald RL, Ray RD: Skeletal traction for the treatment of severe scoliosis. The University of Illinois halo-hoop apparatus. J Bone Joint Surg Am 1970, 52:233-238.

18. Edgar MA, Chapman RH, Glasgow MM: Pre-operative correction in adolescent idiopathic scoliosis. J Bone Joint Surg $\mathrm{Br}$ 1982, 64:530-535.

19. Floman Y, Penny JN, Micheli LJ, Riseborough EJ, Hall JE: Osteotomy of the fusion mass in scoliosis. J Bone Joint Surg Am 1982, 64:1307-1316.

20. Kane WJ, Moe JH, Lai CC: Halo-femoral pin distraction in the treatment of scoliosis. J Bone Joint Surg Am 1967, 49:1018-1019.

21. Bonnett C, Perry J, Brown JC, Greenberg BJ: Halo-femoral distraction and posterior spine fusion for paralytic scoliosis. J Bone Joint Surg Am 1972, 54-A:202.

22. Arlet $V$, Papin P, Marchesi D: Halo femoral traction and sliding rods in the treatment of a neurologically compromised congenital scoliosis:technique. Eur Spine J 1999, 8:329-33I.

23. Leatherman KD, Dickson RA: Two stage corrective surgery for congenital deformity of the spine. J Bone Joint Surg Br I978, 6 IB(3):324-328.

24. Celli $P$, Palatinsky E: Brain abscess as a complication of cranial traction. Surg Neurol 1985, 23:594-596.

25. MacEwen GD, Bunnell WP, Sriram K: Acute neurological complications in the treatment of scoliosis. A report of the Scoliosis Research Society. J Bone Joint Surg Am 1975, 57:404-408.

26. Rinella A, Lenke L, Whitaker C, Kim Y, Park SS, Peelle M, Edwards C II, Bridwell K: Perioperative halo-gravity traction in the treatment of severe scoliosis and kyphosis. Spine 2005, 30:475-482.

27. Cotrel Y, Dubousset J, Guillaumat M: New universal instrumentation in spinal surgery. Clin Orthop 1988, 227:10-23.

28. Li M, Liu Y, Zhu X, Bai Y, Ni C, Shi Z, Hou T: Surgical results of one stage anterior release and posterior correction for treatment of severe scoliosis. Chin J Orthop 2004, 24:27I-275.

Publish with Bio Med Central and every scientist can read your work free of charge

"BioMed Central will be the most significant development for disseminating the results of biomedical research in our lifetime. "

Sir Paul Nurse, Cancer Research UK

Your research papers will be:

- available free of charge to the entire biomedical community

- peer reviewed and published immediately upon acceptance

- cited in PubMed and archived on PubMed Central

- yours - you keep the copyright
BioMedcentral 